\title{
Preoperative prevalence of deep vein thrombosis in patients scheduled to have surgery for degenerative musculoskeletal disorders
}

Keigo Sato ${ }^{1}$, Hideki Date ${ }^{1}$, Takehiro Michikawa², Mitsuhiro Morita ${ }^{1}$, Kazue Hayakawa', Shinjiro Kaneko ${ }^{3}$ and Nobuyuki Fujita ${ }^{*}$

\begin{abstract}
Background: Although the incidence of symptomatic pulmonary thromboembolism after elective surgery for degenerative musculoskeletal disorders is comparatively low, it is extremely detrimental to both patients and health-care providers. Therefore, its prevention is mandatory. We aimed to perform a cross-sectional analysis of deep venous thrombosis (DVT) before elective surgery for degenerative musculoskeletal disorders, including total knee arthroplasty (TKA), total hip arthroplasty (THA), and spinal surgery, and identify the factors associated with the incidence of preoperative DVT.

Methods: The clinical data of patients aged $\geq 30$ years who underwent TKA or THA, and spine surgery for lumbar or cervical degenerative disorders at our institution were retrospectively collected. D-dimer levels were measured preoperatively in all the patients scheduled for surgery. For the patients with D-dimer levels $\geq 1 \mu \mathrm{g} / \mathrm{mL}$ or who were determined by their physicians to be at high risk of DVT, the lower extremity vein was preoperatively examined for DVT on ultrasonography.

Results: Overall, we retrospectively evaluated 1236 consecutive patients, including 701 men and 535 women. Of the patients, 431 and 805 had D-dimer levels $\geq 1$ and $<1 \mu \mathrm{g} / \mathrm{mL}$, respectively. Of 683 patients who underwent lower extremity ultrasonography, 92 had proximal $(n=7)$ and distal types $(n=85)$ of DVT. The preoperative prevalence of DVT was $7.4 \%$. No patient had the incidence of postoperative symptomatic venous thromboembolism. A multivariate analysis revealed that age $\geq 80$ years (odds ratio [OR], $95 \%$ confidence interval [CI]: 2.8, 1.1-7.3), knee surgery (2.1, 1.1-4.0), American Society of Anesthesiologists (ASA) grade 2 (2.8, 1.2-6.8), ASA grades 3 or $4(3.1,1.0-9.4)$, and malignancy $(1.9,1.1-3.2)$ were significantly associated with DVT incidence.
\end{abstract}

\footnotetext{
* Correspondence: nfujita2007@gmail.com

'Department of Orthopaedic Surgery, School of Medicine, Fujita Health University, 1-98 Dengakugakubo, Kutsukake-cho, Aichi, Toyoake, Japan

Full list of author information is available at the end of the article
}

(c) The Author(s). 2021 Open Access This article is licensed under a Creative Commons Attribution 4.0 International License, which permits use, sharing, adaptation, distribution and reproduction in any medium or format, as long as you give appropriate credit to the original author(s) and the source, provide a link to the Creative Commons licence, and indicate if changes were made. The images or other third party material in this article are included in the article's Creative Commons licence, unless indicated otherwise in a credit line to the material. If material is not included in the article's Creative Commons licence and your intended use is not permitted by statutory regulation or exceeds the permitted use, you will need to obtain permission directly from the copyright holder. To view a copy of this licence, visit http://creativecommons.org/licenses/by/4.0/. The Creative Commons Public Domain Dedication waiver (http://creativecommons.org/publicdomain/zero/1.0/) applies to the data made available in this article, unless otherwise stated in a credit line to the data. 
Conclusions: This is the first study to conduct a cross-sectional analysis of preoperative DVT data of patients scheduled for elective surgery for degenerative musculoskeletal disorders. Although whether screening for preoperative DVT is needed to prevent postoperative symptomatic pulmonary thromboembolism remains to be clarified, our data suggested that DVT should be noted before surgery in the patients with advanced age, knee surgery, high ASA physical status, and malignancy.

Keywords: Pulmonary thromboembolism, Deep venous thrombosis, Venous thromboembolism, D-dimer, Degenerative musculoskeletal disorders, Osteoarthritis, Degenerative spinal disorders, Elective surgery

\section{Background}

The number of patients with degenerative musculoskeletal disorders, including knee or hip osteoarthritis and degenerative spinal disorders, is increasing worldwide as the global population ages, and the financial and social costs associated with these conditions are also increasing in several countries $[1,2]$. The therapeutic outcomes of total knee arthroplasty (TKA), total hip arthroplasty (THA), and spinal surgery are generally favorable. However, these procedures are associated with serious postoperative complications such as surgical site infection, postoperative hematoma, implant breakage, or even symptomatic pulmonary thromboembolism (PTE) [3-5].

According to the American Academy of Orthopedic Surgeons guidelines [3], the incidence of symptomatic PTE after TKA and THA is approximately $0.4 \%$, and this complication is fatal in approximately $10 \%$ of the cases. The incidence of symptomatic PTE in spinal surgery is even lower, making it an extremely rare complication. However, symptomatic PTE often leads to sudden postoperative death. As its incidence is extremely detrimental to the patient and health-care providers alike, its prevention is mandatory. Therefore, the following practices are observed in clinical practice to prevent the occurrence of symptomatic PTE: screening for deep venous thrombosis (DVT), perioperative use of compression stockings or an intermittent pneumatic compression device, early postoperative active or passive motion of the knee or hip joint, early mobilization and ambulation, and prophylactic anticoagulant administration [3]. The reported risk factors of symptomatic VTE after surgery for degenerative musculoskeletal disorders include prior occurrence of symptomatic VTE, obesity, advanced age, and paralysis of the legs [3, 6, 7]. Although no current clear evidence supports the usefulness of preoperative screening for DVT by means of Ddimer measurement and ultrasonography for decreasing the incidence of symptomatic VTE, in our institution, we measure preoperative D-dimer level not only for trauma patients but also for all patients scheduled to undergo an elective surgery for a degenerative musculoskeletal disorder. If the level exceeds the reference value, we perform DVT screening by ultrasonography. Previous studies that assessed the incidence of preoperative DVT in patients with degenerative musculoskeletal disorders focused on patients undergoing a single type of surgery, including TKA, THA, or spinal surgery [8-16]. To the best of our knowledge, few single cross-sectional studies have considered all these surgeries in the assessment of the preoperative prevalence of DVT. Therefore, in this study, we aimed to perform a cross-sectional analysis of the incidence of DVT before elective surgery for degenerative musculoskeletal disorders in our institution and to identify the factors associated with the preoperative DVT.

\section{Methods \\ Study participants}

The clinical data of patients aged $\geq 30$ years who underwent TKA or unicompartmental knee arthroplasty (UKA), THA, and decompression and/or fixation spine surgery for lumbar or cervical degenerative disorders at our institution between January 2018 and December 2019 were retrospectively collected. TKA or UKA was performed for osteoarthritis, rheumatoid arthritis, and idiopathic osteonecrosis of the knee. THA was performed for osteoarthritis and rheumatoid arthritis of the hip and osteonecrosis of the femoral head. Spine surgery included both the anterior and posterior approaches. In our institution, D-dimer level in peripheral blood was measured preoperatively in all the patients scheduled for an orthopedic surgery (Fig. 1). For the patients with Ddimer levels $\geq 1 \mu \mathrm{g} / \mathrm{mL}$ or who were determined by the subjective judgment of physicians to be at high risk of DVT, the lower extremity vein was preoperatively examined for DVT on ultrasonography (Fig. 1). The value of D-dimer was converted by DD units in the present study. All the patients without preoperative DVT were fitted with both compression stockings and an intermittent pneumatic compression device in the perioperative period, and left bed and started walking on the first postoperative day. Meanwhile, in the patients with preoperative DVT, the protocol with compression stockings and an intermittent pneumatic compression device in the perioperative period was modified for each patient. All the patients with preoperative DVT received preoperative antithrombotic therapy including heparinization and/or oral administration of active factor 


\section{The patients $\geq 30$ years old who scheduled to undergo}

- Total knee arthroplasty or unicompartmental knee arthroplasty

- Total hip arthroplasty

- Spine surgery for lumbar or cervical degenerative disorders

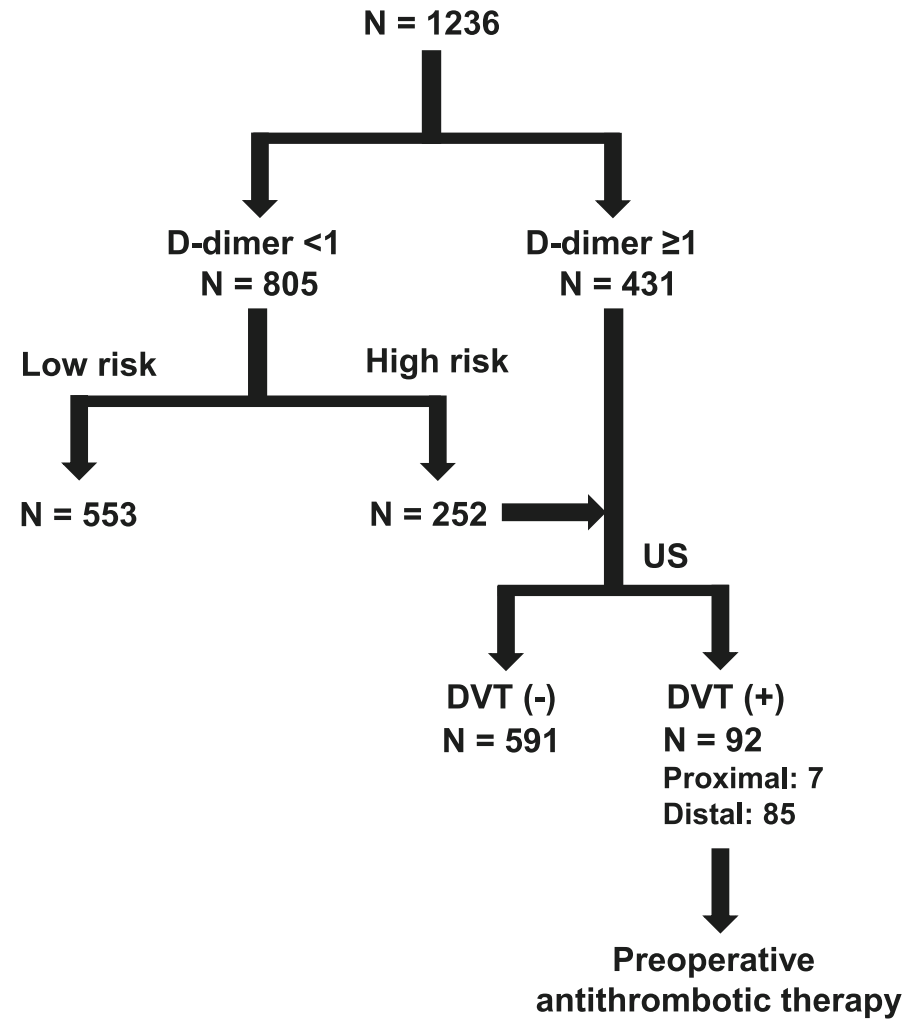

Fig. 1 Flowchart of the screening for preoperative deep vein thrombosis (DVT). US, ultrasonography

Xa inhibitors. The choice of treatment, dose, and duration were determined by each patient's physician. The patients with TKA/UKA and THA started continuous passive motion of the knee and hip joints on the first postoperative day, and oral administration of active factor Xa inhibitors for 7 days from the second postoperative day. Meanwhile, the patients with spinal surgery did not have postoperative antithrombotic therapy for avoiding spinal epidural hematoma. No patient was preoperatively placed with inferior vena cava filter.

\section{Ethics approval and consent to participate}

Ethical approval for this study was granted by Fujita Health University Ethics Committee (approval No. HM20-055). The informed consent was waived by the Fujita Health University Ethics Committee. Fujita Health University Ethics Committee also approved the opt-out consent process, meaning that all eligible people were included in this study unless they contacted us to opt out. No administrative permissions and/or licenses were required to access the clinical/personal patient data used in this research. All methods in the study were carried out in accordance with the Helsinki guidelines and declaration or any other relevant guidelines.

\section{Diagnosis of DVT}

Linear and convex probes (Canon, Tokyo, Japan) were used to perform pulse Doppler ultrasonographic examinations of the lower extremities of the patients. The transducer frequency was set from $7.5 \mathrm{MHz}$ to $12 \mathrm{MHz}$. The diagnostic criteria for DVT are a filling defect of the cavity, incompressibility of the vein, and lack of Doppler signal. Routine scanning for vein thrombosis was performed for the common femoral, femoral, popliteal, posterior tibial, peroneal, soleal, and sural veins of the bilateral lower extremities. In the case of common femoral, femoral, and popliteal veins, it was diagnosed as the proximal type. Meanwhile, in the case of posterior tibial, 
peroneal, soleal, and sural veins, it was diagnosed as the distal type.

\section{Data collection}

The following data were evaluated: age, body mass index (BMI), sex, surgical site, American Society of Anesthesiologists (ASA) physical status grade, and medical history, including hypertension, hyperlipidemia, diabetes, stroke, malignancy, and smoking.

\section{Statistical analyses}

Data are presented as mean \pm standard deviation. The Mann-Whitney $U$ test, Pearson chi-square test, or analysis of variance was used for the statistical analysis. Multiple comparisons among the four groups, including the knee, hip neck, and low back, were performed using the Dunnett test. To examine the independent associations of DVT, we constructed a logistic regression model that included age, sex, BMI, surgical site, ASA grade, hypertension, hyperlipidemia diabetes, stroke, and malignancy, and the estimated odds ratios (ORs) and 95\% confidence intervals (CIs) for DVT. Logistic regression was performed by using the Stata 14 software (Stata Corporation, College Station, TX). $P$ values $<0.05$ were considered as indicating statistical significance.

\section{Results}

Overall, we retrospectively reviewed 1236 consecutive patients (701 men and 535 women) in the present study. The patients' baseline characteristics, including age, sex, BMI, surgical site, and medical history, are summarized in Table 1. Figure 1 presents the flowchart for the examination for DVT. Of the patients, 431 had D-dimer levels $\geq 1 \mu \mathrm{g} / \mathrm{mL}$ and 805 had D-dimer levels $<1 \mu \mathrm{g} / \mathrm{mL}$. The patients with D-dimer levels $\geq 1 \quad(n=431)$ and < $1 \mu \mathrm{g} / \mathrm{mL}$, who were judged by the physician to have a high risk of DVT $(n=252)$, underwent DVT examination of the lower extremity veins on ultrasonography. Of the 683 patients who underwent lower extremity ultrasonography, 92 had proximal $(n=7)$ and distal types $(n=85)$ of DVT. The preoperative prevalence of DVT was $7.4 \%$. In one patient with preoperative leg edema, surgery was delayed $(n=1)$. Consequently, no patient had the incidence of postoperative symptomatic VTE. Figure 2 showed the mean D-dimer level in the patients with and without DVT. We confirmed that the mean Ddimer level in the patients with DVT was significantly higher than that in the patients without DVT (Fig. 2). The features of DVT were summarized in Table 2.

Next, we independently examined the mean D-dimer level and the prevalence of DVT at four surgical sites,
Table 1 Baseline characteristics $(n=1236)$

\begin{tabular}{lll}
\hline Age (y) & $<50$ & $134(10.8 \%)$ \\
& $50-59$ & $166(13.4 \%)$ \\
& $60-69$ & $289(23.4 \%)$ \\
& $70-79$ & $467(37.8 \%)$ \\
& $\geq 80$ & $180(14.6 \%)$ \\
Sex & Men & $701(56.7 \%)$ \\
Group & Women & $535(43.3 \%)$ \\
& knee & $211(17.1 \%)$ \\
& hip & $328(26.5 \%)$ \\
BMl (kg/m $\left.{ }^{2}\right)$ & neck & $174(14.1 \%)$ \\
& low back & $523(42.3 \%)$ \\
& $<18.5$ & $53(4.3 \%)$ \\
Hypertension & $18.5-24.9$ & $674(54.5 \%)$ \\
Hyperlipidemia & $\geq 25.0$ & $509(41.2 \%)$ \\
Diabetes & $643(52.0 \%)$ & \\
Stroke & $300(24.3 \%)$ & \\
Malignancy & $262(21.2 \%)$ & \\
Smoking & $82(6.6 \%)$ & \\
\hline BMI Body mass & $146(11.8 \%)$ & \\
& $523(42.3 \%)$ & \\
& & \\
& &
\end{tabular}

BMI Body mass index

namely the knee, hip, neck, and low back (Table 3). The mean D-dimer level and incidence of DVT in the knee

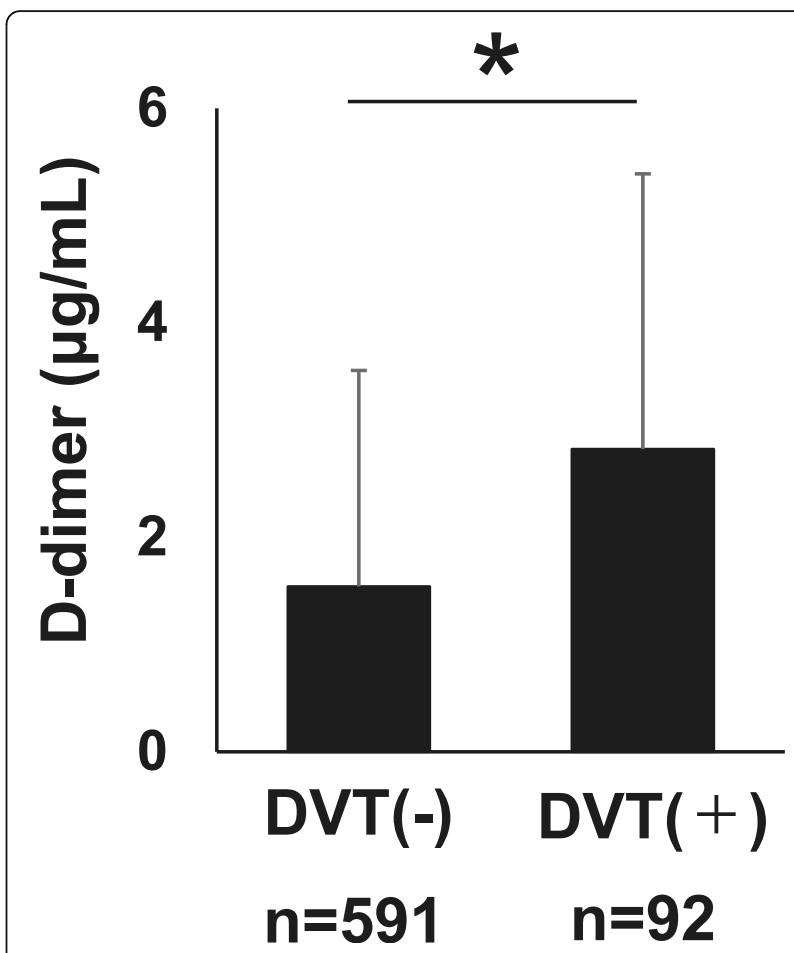

Fig. 2 Comparison of the mean D-dimer level in the patients with and those without DVT. Data are presented as mean \pm SD. ${ }^{*} p<0.05$ 
Table 2 Characteristics of deep venous thrombosis ( $n=92$ )

\begin{tabular}{lll}
\hline Location & Proximal & 7 \\
& Distal & 85 \\
Unilateral or & Unilateral & 78 \\
Bilateral & Bilateral & 14 \\
Fresh & Yes & 85 \\
& No & 7 \\
Symptomatic & Yes & 1 (leg \\
& & edema) \\
& No & 91 \\
\hline
\end{tabular}

group were significantly higher than those in the other groups (Table 3). The mean age and BMI associated with the development of DVT [3,6] were also significantly higher in the knee group than in the other groups (Table 3).

In the uni-variable analysis, DVT was statistical significantly associated with age, sex, surgical site, smoking, ASA, hypertension, and malignancy (Table 4). We constructed a multivariate model included all these variables, and found that age $\geq 80$ years (OR, 2.8; $95 \% \mathrm{CI}$, 1.1-7.3; reference, 50-59 years), knee surgery (OR, 2.1; $95 \% \mathrm{CI}, 1.1-4.0$; reference, hip surgery), ASA grade 2 (OR, 2.8; $95 \%$ CI, 1.2-6.8; reference, ASA grade 1), ASA grade 3 or 4 (OR, 3.1; $95 \%$ CI, 1.0-9.4; reference, ASA grade 1), and malignancy (OR, 1.9; $95 \% \mathrm{CI}, 1.1-3.2)$ were significantly associated with DVT (Table 4).

\section{Discussion}

To the best of our knowledge, this is the first study to conduct a cross-sectional analysis of preoperative DVT data of patients scheduled for elective surgery for degenerative musculoskeletal disorders. Our data showed that the preoperative prevalence of DVT in the patients scheduled to have surgery for degenerative musculoskeletal disorders was $7.4 \%$. In addition, our analysis revealed that the factors associated with preoperative DVT were advanced age, knee surgery, high ASA physical status, and malignancy.
According to the American College of Chest Physicians' evidence-based clinical practice guideline (ACCP), TKA and THA themselves are risk factors of DVT [4]. In the present study, $6.1 \%$ of the patients scheduled for THA had DVT, even before the surgery. This proportion is consistent with those reported in previous studies (5.2-12.3\%) [8-10]. Although DVT screening methods, either ultrasonography or computed tomography, differ among studies, previous studies reported the discrepancies in the frequency of preoperative DVT in TKA (2.6$11.7 \%)$ as well as THA [11-13]. The prevalence of preoperative DVT in TKA in the present study was $14.7 \%$, which is higher than those in previous studies. Owing to issues on radiation exposure with CT [17], ultrasonography will probably be the main method used in screening for preoperative DVT. Furthermore, the advancements in ultrasonography technology could continuously increase the detection rate of preoperative DVT [18]. Although D-dimer has the high rate of false positives for detecting DVT [19], we measured D-dimer levels in all patients as a simple screening tool for DVT in the present study. As expected, our data showed that the D-dimer levels were significantly higher in the patients with than in those without preoperative DVT. The cutoff D-dimer level in the first DVT screening was $1.0 \mu \mathrm{g} / \mathrm{mL}$ in the present study, although the ideal value has yet to be determined and is a topic for future research.

The multivariate analysis in the present study revealed that knee surgery with TKA or UKA is one of the factors associated with the preoperative DVT. Besides knee surgery, the other factors found to be associated with preoperative DVT in our analysis were advanced age, ASA physical status, and malignancy, which were consistent with the previously reported risk factors of postoperative VTE $[3,20]$. In patients with knee osteoarthritis, restricted knee flexion and extension due to knee pain or limited joint range of motion may result in DVT prevalence in the veins of the lower extremities. In addition, Baker's cyst, commonly associated with knee osteoarthritis, has been reported to compress the neurovascular bundle in the popliteal fossa [21]. Therefore, cysts around the knee joint that are associated with knee

Table 3 Comparison among different surgical sites

\begin{tabular}{|c|c|c|c|c|c|}
\hline & knee (211) & hip (328) & neck (174) & low back (523) & $P^{*}$ value \\
\hline Age (y) & $74.0 \pm 8.6$ & $66.6 \pm 11.7^{* *}$ & $63.4 \pm 13.5^{* *}$ & $66.4 \pm 14.3^{* *}$ & $<0.01$ \\
\hline Male/ Female & $50 / 161$ & $53 / 275$ & $126 / 48$ & 306 / 217 & $<0.01$ \\
\hline BMI $\left(\mathrm{kg} / \mathrm{m}^{2}\right)$ & $26.2 \pm 4.6$ & $24.0 \pm 3.9^{* *}$ & $24.0 \pm 3.5^{*} *$ & $24.6 \pm 4.2^{* *}$ & $<0.01$ \\
\hline D-dimer ( $\mu \mathrm{g} / \mathrm{mL})$ & $1.85 \pm 2.99$ & $1.32 \pm 1.38^{* *}$ & $0.86 \pm 10.08^{*} *$ & $1.00 \pm 1.40 * *$ & $<0.01$ \\
\hline DVT (\%) & $14.7 \%(31)$ & $6.1 \%(20)$ & $4.0 \%$ (7) & 6.3 \% (34) & $<0.01$ \\
\hline
\end{tabular}

* ANOVA or $x^{2}$ test.

* $P<0.05$ (Dunnett test; reference $=$ group knee).

$B M I$ Body mass index 
Table 4 Logistic regression analysis of DVT

\begin{tabular}{|c|c|c|c|c|c|c|c|c|c|c|c|c|}
\hline \multirow{3}{*}{ Age (y) } & \multirow[b]{3}{*}{$<50$} & \multirow{3}{*}{$\begin{array}{l}\text { Number } \\
\text { of } \\
\text { patients }\end{array}$} & \multirow{3}{*}{$\begin{array}{l}\text { Number } \\
\text { of DVT }\end{array}$} & \multirow{3}{*}{$\begin{array}{l}\text { Rate } \\
\text { of } \\
\text { DVT } \\
\text { (\%) }\end{array}$} & \multicolumn{4}{|c|}{ Uni-variable analysis } & \multicolumn{4}{|c|}{ Multi-variable analysis } \\
\hline & & & & & \multirow{2}{*}{$\begin{array}{l}\text { OR } \\
0.20\end{array}$} & \multicolumn{2}{|c|}{$95 \% \mathrm{Cl}$} & \multirow{2}{*}{$\begin{array}{l}\boldsymbol{p} \text {-value } \\
0.14\end{array}$} & \multirow{2}{*}{$\begin{array}{l}\text { OR } \\
0.24\end{array}$} & \multicolumn{2}{|c|}{$95 \% \mathrm{Cl}$} & \multirow{2}{*}{$\frac{p \text {-value }}{0.20}$} \\
\hline & & & & & & 0.02 & 1.69 & & & 0.03 & 2.07 & \\
\hline & $50-59$ & 166 & 6 & 3.6 & reference & & & & & & & \\
\hline & $60-69$ & 289 & 19 & 6.6 & 1.88 & 0.73 & 4.80 & 0.19 & 1.46 & 0.56 & 3.81 & 0.44 \\
\hline & $70-79$ & 467 & 40 & 8.6 & 2.50 & 1.04 & 6.01 & 0.04 & 1.71 & 0.69 & 4.23 & 0.25 \\
\hline & $>=80$ & 180 & 26 & 14.4 & 4.50 & 1.80 & 11.24 & $<0.01$ & 2.83 & 1.09 & 7.31 & 0.03 \\
\hline \multirow[t]{2}{*}{ Sex } & Men & 535 & 25 & 4.7 & reference & & & & & & & \\
\hline & Women & 701 & 67 & 9.6 & 2.16 & 1.34 & 3.46 & $<0.001$ & 1.82 & 0.97 & 3.39 & 0.06 \\
\hline \multirow[t]{4}{*}{ Group } & knee & 211 & 31 & 14.7 & 2.65 & 1.47 & 4.79 & 0.00 & 2.12 & 1.13 & 3.96 & 0.02 \\
\hline & hip & 328 & 20 & 6.1 & reference & & & & & & & \\
\hline & neck & 174 & 7 & 4.0 & 0.65 & 0.27 & 1.56 & 0.33 & 0.98 & 0.38 & 2.49 & 0.96 \\
\hline & low back & 523 & 34 & 6.5 & 1.07 & 0.61 & 1.89 & 0.81 & 1.27 & 0.68 & 2.38 & 0.45 \\
\hline \multirow[t]{3}{*}{ BMI (kg/m2) } & $<18.5$ & 53 & 7 & 13.2 & 1.78 & 0.76 & 4.13 & 0.18 & & & & \\
\hline & $18.5-24.9$ & 674 & 53 & 7.9 & reference & & & & & & & \\
\hline & $>=25.0$ & 509 & 32 & 6.3 & 0.78 & 0.50 & 1.23 & 0.29 & & & & \\
\hline \multirow[t]{2}{*}{ Smoking } & No & 713 & 63 & 8.8 & reference & & & & & & & \\
\hline & Yes & 523 & 29 & 5.5 & 0.60 & 0.38 & 0.95 & 0.03 & 1.08 & 0.60 & 1.92 & 0.81 \\
\hline \multirow[t]{3}{*}{ ASA } & 1 & 253 & 6 & 2.4 & reference & & & & & & & \\
\hline & 2 & 856 & 73 & 8.5 & 3.84 & 1.65 & 8.93 & 0.00 & 2.80 & 1.15 & 6.83 & 0.02 \\
\hline & 3,4 & 104 & 10 & 9.6 & 4.38 & 1.55 & 12.39 & 0.01 & 3.13 & 1.04 & 9.41 & 0.04 \\
\hline \multirow[t]{2}{*}{ Hypertension } & No & 593 & 35 & 5.9 & reference & & & & & & & \\
\hline & Yes & 643 & 57 & 8.9 & 1.55 & 1.00 & 2.40 & 0.05 & 0.87 & 0.54 & 1.41 & 0.57 \\
\hline \multirow[t]{2}{*}{ Hyperlipidemia } & No & 936 & 67 & 7.2 & reference & & & & & & & \\
\hline & Yes & 300 & 25 & 8.3 & 1.18 & 0.73 & 1.90 & 0.50 & & & & \\
\hline \multirow[t]{2}{*}{ Diabetes } & No & 974 & 76 & 7.8 & reference & & & & & & & \\
\hline & Yes & 262 & 16 & 6.1 & 0.77 & 0.44 & 1.34 & 0.35 & & & & \\
\hline \multirow[t]{2}{*}{ Stroke } & No & 1,154 & 86 & 7.5 & reference & & & & & & & \\
\hline & Yes & 82 & 6 & 7.3 & 0.98 & 0.42 & 2.32 & 0.96 & & & & \\
\hline \multirow[t]{2}{*}{ Malignancy } & No & 1,090 & 73 & 6.7 & reference & & & & & & & \\
\hline & Yes & 146 & 19 & 13.0 & 2.08 & 1.22 & 3.57 & 0.01 & 1.85 & 1.06 & 3.23 & 0.03 \\
\hline
\end{tabular}

$B M I$ Body mass index

osteoarthritis may increase the frequency of DVT. In the future, the relationship between knee osteoarthritis severity and incidence of DVT should be examined.

According to the ACCP, the risk of VTE is considered moderate in spinal surgeries for malignant diseases but relatively low in elective surgeries for degenerative spinal disorders [4]. Recently, Winther et al. reported that the incidence of symptomatic VTE in elective surgeries for degenerative spinal disorders was $0.2 \%$ [14]. Meanwhile, Takahashi et al. retrospectively examined elective spinal surgeries in a group of patients who underwent the procedure to prevent VTE and in a group who did not [22]. They found that the incidence of symptomatic PTE was significantly lower in the preventive VTE group [22].
Therefore, although the frequency of elective surgeries for degenerative spinal disorders is low, preventing VTE is observed to be important, as well as performing TKA and THA. According to Liu et al., the incidence of preoperative DVT in patients with cervical spondylotic myelopathy scheduled for spinal surgery was $4 \%$, which is similar to the results of this study [15]. Meanwhile, Yamasaki et al. found that the incidence of preoperative DVT in elective lumbar spine surgeries was $7.7 \%$ when the vertebral body fracture group was excluded [16], which is also similar to the lumbar surgery data from the present study. As the population ages, patients undergoing elective surgeries for degenerative spinal disorders will be older, their ASA physical status will be 
higher, and majority of them will have malignancies. Therefore, the risk of VTE incidence is also expected to continuously increase, making symptomatic VTE prevention in patients undergoing elective surgeries for degenerative spinal disorders even more important.

This study has several limitations. First, our data were retrospectively collected from a limited number of patients in a single institution. Second, a selection bias exists in this study because ultrasonography was added as a screening procedure in the patients with $\mathrm{D}$-dimer levels $<1 \mu \mathrm{g} / \mathrm{mL}$, whose attending physicians made a subjective assessment of high DVT risk. An objective evaluation including the Caprini scale was not performed when clarifying patients with high DVT risk. Third, because the occurring of DVT does not mean episode of a fatal PTE, the present study did not have a screen of PTE. Fourth, whether screening for preoperative DVT is needed to prevent postoperative symptomatic VTE remains to be clarified. Chang et al. reported that routine preoperative DVT evaluation is probably not necessary [23]. However, if patients scheduled for elective surgery for degenerative musculoskeletal disorders have DVT before the surgery, the risks of thrombus extension and fatal PTE could be higher. Whether DVT screening through preoperative D-dimer measurements or ultrasonography can reduce the incidence of symptomatic VTE remains to be verified using large-scale data. Nevertheless, our cross-sectional analysis clearly identified the factors associated with preoperative DVT in patients with degenerative musculoskeletal disorders.

\section{Conclusions}

We conducted a cross-sectional analysis of the prevalence of preoperative DVT in patients scheduled to undergo elective surgery for degenerative musculoskeletal disorders. Our data suggest that DVT should be noted before surgery in patients with advanced age, knee surgery, high ASA physical status, and malignancy.

\section{Abbreviations \\ TKA: Total knee arthroplasty; THA: Total hip arthroplasty; PTE: Pulmonary thromboembolism; DVT: Deep vein thrombosis; VTE: Venous thromboembolism}

\section{Acknowledgements}

None.

\section{Authors' contributions}

N.F. designed the study and wrote the initial draft of the manuscript. K.S., D.H., T.M., K.H., M.M., and S.K. contributed to the analysis and interpretation of data. T.M. performed the statistical analysis. K.S., D.H., T.M., K.H., M.M., and S.K. critically reviewed the manuscript. All authors have read and agreed to the published version of the manuscript.

\section{Funding}

This research received no external funding.

\section{Availability of data and materials}

The datasets generated and/or analysed during the current study are not publicly available due to limitations of ethical approval involving the patient data and anonymity but are available from the corresponding author on reasonable request.

\section{Declarations}

Ethics approval and consent to participate

This research was approved by Fujita Health University Ethics Committee (approval No. HM20-055). Informed consent with Fujita Health University Ethics Committee was obtained in the form of opt-out on the web-site.

\section{Consent for publication}

Not applicable.

\section{Competing interests}

There are no conflicts of interest to declare.

\section{Author details}

${ }^{1}$ Department of Orthopaedic Surgery, School of Medicine, Fujita Health University, 1-98 Dengakugakubo, Kutsukake-cho, Aichi, Toyoake, Japan. ${ }^{2}$ Department of Environmental and Occupational Health, School of Medicine, Toho University, Tokyo, Japan. ${ }^{3}$ Department of Spine and Spinal Cord Surgery, Fujita Health University, Aichi, Toyoake, Japan.

Received: 31 January 2021 Accepted: 21 May 2021

Published online: 04 June 2021

\section{References}

1. Ageing and health. https://www.who.int/news-room/fact-sheets/detail/a geing-and-health. 18 Jan 2021.

2. Woolf $A D$, Pfleger B. Burden of major musculoskeletal conditions. Bull World Health Organ. 2003;81(9):646-56.

3. Jacobs JJ, Mont MA, Bozic KJ, Della Valle CJ, Goodman SB, Lewis CG, et al. American Academy of Orthopaedic Surgeons clinical practice guideline on: preventing venous thromboembolic disease in patients undergoing elective hip and knee arthroplasty. J Bone Joint Surg Am. 2012;94(8):746-7.

4. Falck-Ytter Y, Francis CW, Johanson NA, Curley C, Dahl OE, Schulman S, et al. Prevention of VTE in orthopedic surgery patients: Antithrombotic Therapy and Prevention of Thrombosis, 9th ed: American College of Chest Physicians Evidence-Based Clinical Practice Guidelines. Chest. 2012;141(2 Suppl):e278S-e325S.

5. White $\mathrm{RH}$, Zhou H, Romano PS. Incidence of symptomatic venous thromboembolism after different elective or urgent surgical procedures. Thromb Haemost 2003:90(3):446-55.

6. Darvall KA, Sam RC, Silverman SH, Bradbury AW, Adam DJ. Obesity and thrombosis. Eur J Vasc Endovasc Surg 2007:33(2):223-33.

7. Turpie AG, Levine MN, Hirsh J, Carter CJ, Jay RM, Powers PJ, et al. Doubleblind randomised trial of Org 10172 low-molecular-weight heparinoid in prevention of deep-vein thrombosis in thrombotic stroke. Lancet 1987; 1(8532):523-6.

8. Kawai T, Goto K, Kuroda Y, Matsuda S. Lower activity and function scores are associated with a higher risk of preoperative deep venous thrombosis in patients undergoing total hip arthroplasty. J Clin Med 2020;9(5):1257.

9. Wakabayashi H, Hasegawa M, Niimi R, Sudo A. Clinical analysis of preoperative deep vein thrombosis risk factors in patients undergoing total hip arthroplasty. Thromb Res 2015 Nov;136(5):855-8.

10. Imai N, Miyasaka D, Shimada H, Suda K, Ito T, Endo N. Usefulness of a novel method for the screening of deep vein thrombosis by using a combined Ddimer- and age-based index before total hip arthroplasty. PLoS One 2017; 12(2):e0172849.

11. Kim KI, Cho KY, Jin W, Khurana SS, Bae DK. Recent Korean perspective of deep vein thrombosis after total knee arthroplasty. J Arthroplast 2011;26(7): 1112-6.

12. Watanabe $H$, Sekiya $H$, Kariya $Y$, Hoshino $Y$, Sugimoto $H$, Hayasaka S. The incidence of venous thromboembolism before and after total knee arthroplasty using 16-row multidetector computed tomography. J Arthroplast 2011;26(8):1488-93.

13. Niki $Y$, Matsumoto $H$, Hakozaki A, Mochizuki T, Momohara S. Rheumatoid arthritis: a risk factor for deep venous thrombosis after total knee 
arthroplasty? Comparative study with osteoarthritis. J Orhthop Sci 2010; 15(1):57-63.

14. Winther CF, Thomsen $K$, Sørensen LP, Jenstrup M, Thomsen FB. Venous thromboembolic complications following surgical treatment for degenerative spinal disease. Dan Med J 2019;66(5):A5541.

15. Liu L, Liu YB, Sun JM, Hou HF, Liang C, Li T, et al. Preoperative deep vein thrombosis in patients with cervical spondylotic myelopathy scheduled for spinal surgery. Medicine (Baltimore). 2016;95(44):e5269.

16. Yamasaki K, Hoshino M, Omori K, Igarashi H, Tsuruta T, Miyakata H, et al. Prevalence and risk factors of deep vein thrombosis in patients undergoing lumbar spine surgery. J Orthop Sci. 2017;22(6):1021-5.

17. Brenner DJ, Hall EJ. Computed tomography-an increasing source of radiation exposure. N Engl J Med 2007;357(22):2277-84

18. Guyatt GH, Norris SL, Schulman S, Hirsh J, Eckman MH, Akl EA, et al. Methodology for the development of antithrombotic therapy and prevention of thrombosis guidelines: Antithrombotic Therapy and Prevention of Thrombosis, 9th ed: American College of Chest Physicians Evidence-Based Clinical Practice Guidelines. Chest. 2012;141(2 Suppl):53S705 .

19. Kelly J, Rudd J, Lewis RR, Hunt BJ. Plasma D-dimers in the diagnosis of venous thromboembolism. Arch Intern Med. 2002;162(7):747-56.

20. Shaikh MA, Jeong HS, Mastro A, Davis K, Lysikowski J, Kenkel JM. Analysis of the American Society of Anesthesiologists Physical Status Classification System and Caprini Risk Assessment Model in predicting venous thromboembolic outcomes in plastic surgery patients. Aesthet Surg J. 2016; 36(4):497-505.

21. Sanchez JE, Conkling N, Labropoulos N. Compression syndromes of the popliteal neurovascular bundle due to Baker cyst. J Vasc Surg 2011;54(6): 1821-9.

22. Takahashi H, Yokoyama Y, lida Y, Terashima F, Hasegawa K, Saito T, et al. Incidence of venous thromboembolism after spine surgery. J Orthop Sci. 2012;17(2):114-7.

23. Chang MJ, Song MK, Kyung MG, Shin JH, Chang CB, Kang SB. Incidence of deep vein thrombosis before and after total knee arthroplasty without pharmacologic prophylaxis: a 128-row multidetector CT indirect venography study. BMC Musculoskelet Disord. 31 Jul 2018;19(1):274

\section{Publisher's Note}

Springer Nature remains neutral with regard to jurisdictional claims in published maps and institutional affiliations.

Ready to submit your research? Choose BMC and benefit from:

- fast, convenient online submission

- thorough peer review by experienced researchers in your field

- rapid publication on acceptance

- support for research data, including large and complex data types

- gold Open Access which fosters wider collaboration and increased citations

- maximum visibility for your research: over $100 \mathrm{M}$ website views per year

At BMC, research is always in progress.

Learn more biomedcentral.com/submissions 